\title{
Brain imaging of pain sensitization in patients with knee osteoarthritis
}

Jesus Pujol, MD ${ }^{1,2}$; Gerard Martínez-Vilavella, MSc${ }^{1}$; Jone Llorente-Onaindia, $\mathrm{MSc}^{3}$; Ben J. Harrison, $\mathrm{PhD}^{4}$; Marina López-Solà, $\mathrm{PhD}^{5}$; Marina López-Ruiz, MSC ${ }^{3}$; Laura Blanco-Hinojo, $\mathrm{PhD}^{1,2}$; Pere Benito, $\mathrm{MD}^{3}$; Joan Deus, $\mathrm{PhD}^{1,6}$; Jordi Monfort, $\mathrm{MD}^{3}$

${ }^{1}$ MRI Research Unit, Department of Radiology, Hospital del Mar, Barcelona, Spain.

${ }^{2}$ Centro Investigación Biomédica en Red de Salud Mental, CIBERSAM G21, Barcelona, Spain. ${ }^{3}$ Rheumatology Department, Hospital del Mar, Barcelona, Spain.

${ }^{4}$ Melbourne Neuropsychiatry Centre, Department of Psychiatry, The University of Melbourne and Melbourne Health, Melbourne, Australia.

${ }^{5}$ Department of Anesthesiology. Cincinnati Children's Hospital. Cincinnati, Ohio, USA.

${ }^{6}$ Department of Clinical and Health Psychology, Autonomous University of Barcelona, Barcelona, Spain.

The submission contains: The main text file (double-spaced 25 pages). Four Figures. One Table. One supplemental content file.

\section{The authors declare no competing interests.}

Corresponding author: Dr. Jesus Pujol. MRI Department, Hospital del Mar, Passeig Marítim 25-29. 08003, Barcelona, Spain. Email: 21404jpn@ comb.cat Telephone: +34932212180 Fax: +34932212181 


\section{Abstract}

A relevant aspect in osteoarthritic pain is neural sensitization. This phenomenon involves augmented responsiveness to painful stimulation and may entail a clinically worse prognosis. We used functional MRI (fMRI) to study pain sensitization in patients with knee osteoarthritis. Sixty patients were recruited and pain sensitization was clinically defined on the basis of regional spreading of pain (spreading sensitization) and increased pain response to repeated stimulation (temporal summation). fMRI testing involved assessing brain responses to both pressure and heat stimulation. Thirty-three patients (55\%) showed regional pain spreading (simple sensitization) and 19 patients $(32 \%)$ showed both regional spreading and temporal summation. Sensitized patients were more commonly women. Direct painful pressure stimulation of the joint (articular interline) robustly activated all of the neural elements typically involved in pain perception, but did not differentiate sensitized and non-sensitized patients. Painful pressure stimulation on the anterior tibial surface (sensitized site) evoked greater activation in sensitized patients in regions typically involved in pain and also beyond these regions, extending to the auditory, visual and ventral sensorimotor cortices. Painful heat stimulation of the volar forearm did not discriminate the sensitization phenomenon. Results confirm the high prevalence of pain sensitization secondary to knee osteoarthritis. Relevantly, the sensitization phenomenon was associated with neural changes extending beyond strict pain-processing regions with enhancement of activity in general sensory, non-nociceptive brain areas. This effect is in contrast with the changes previously identified in primary pain sensitization in fibromyalgia patients presenting with a weakening of general sensory integration. 


\section{Introduction}

Patients with osteoarthritis (OA) of the knee typically experience pain from joint injury. However, their sensation of pain is often augmented as a consequence of neural sensitization occurring in nociceptors, spinal cord pathways and the brain $[1,5]$. Patients with pain sensitization can be identified on the basis of regional spreading of pain (spreading sensitization) and increased pain response to repeated stimulation (temporal summation) [4,34]. The sensitization phenomenon is of major clinical relevance, as pain uses to be more severe in sensitized patients, while conventional analgesics may be less effective $[14,17,30]$. Moreover, self-report and sensory measurements of pain sensitization have been shown to predict poorer long-term outcome after joint replacement $[7,18,24,25]$.

In recent years, pain sensitization has received increased attention both in clinical and research studies $[5,16,19,23]$. However, the ultimate effects of pain sensitization on brain functioning are unknown. Such information may be relevant to the optimized treatment of OA patients, particularly regarding the provision of therapeutic options that have a stronger neurobiological rationale and the brain as a potential target. Functional brain imaging has emerged as an optimal means to assess the response to painful stimulation and characterize its multiple dimensions $[8,22,32]$. We used functional MRI (fMRI) to study pain sensitization in a clinical sample of patients with knee OA. The presence and severity of pain sensitization was clinically defined using operative criteria, and our imaging testing included direct pressure stimulation of the painful knee joint and pressure stimulation on a surrounding sensitized site. In addition, painful heat stimulation was applied to the forearm to assess the degree of generalization of the sensitization phenomenon to other body areas and other pain modalities. 


\section{Materials and Methods}

\section{Participants}

Participants were recruited from a referral OA Unit at the Hospital del Mar, Barcelona. Inclusion to the study was consecutive in follow-up clinical visits during a period of 18 months. The current medical status of each case was revised $(n=393)$ and those cases fulfilling the study's eligibility criteria were invited to participate $(n=88)$. A final total of 60 patients provided written informed consent to participate.

Eligibility criteria included: (i) a clinical and radiological diagnosis of knee OA based upon the criteria of the American College of Rheumatology [2]; (ii) current age greater than 44 years; (iii) symptoms affecting at least one knee with a minimum duration of 3 months prior to screening; (iv) a clinical pain intensity (index knee; 24h-average pain) ranging between 4 and 8 on an 11-point numerical rating scale (NRS) at screening and/or the need for the use of analgesics.

Clinical evaluations. Clinical history and physical examination, ECG, X-ray of the knee, Brief Pain Inventory [11], Western Ontario and McMaster Universities Osteoarthritis Index (WOMAC) physical-function scale [10], PainDETECT questionnaire [12] and the study-specific pain assessment (see below).

Participant restrictions. Baseline pain was required to be stable for at least 72 hours and heavy exercise was not permitted for 12 hours prior to fMRI. Patients were required to refrain from analgesic and anti-inflammatory drugs for 3 days and rescue medication (paracetamol $1 \mathrm{~g} / 8 \mathrm{~h}$ maximum) for 1 day prior to fMRI. In addition, no patients were being treated with steroid ( 3 months) or hyaluronan ( 6 months) injections before 
inclusion, or currently treated with antidepressants or pain killer anticonvulsants (only SSRIs were permitted in case of chronic use).

Twenty-four participants were recruited as a control group to inform on the normal brain response to knee pressure stimulation in absence of symptomatic knee OA. Participants were either friends or family of OA patients, or were recruited from local advertisements. Participants older than 44 years were included, none with any clinically relevant or non-compensated medical disorder, neurological/psychiatric disease, psychiatric medication, or pain disorders. No control subject had received a diagnosis of knee OA and none acknowledged usual/relevant knee OA symptoms in a specific anamnesis at inclusion. However, according to subjective scoring (Table 1), occasional, mild knee pain was present in this group, as would be expected in an aged population. All provided written informed consent to participate.

The study was approved by the local Ethics Committee (Clinical Research Ethical Committee-Institut Municipal d'Assistència Sanitària (CEIC-IMAS), Barcelona), and was conducted in compliance with the Code of Ethics of the World Medical Association (Declaration of Helsinki).

\section{Pain sensitization assessment}

Criteria. Pain sensitization was clinically defined on the basis of evidence of regional spreading of pain (spreading sensitization) and increased pain response to repeated stimulation (temporal summation) [4,17,34]. Operatively, patients were considered sensitized to some degree (simple sensitization) when showing clinical evidence of altered sensations spread beyond the knee joint by manual palpation and a minimum of 2 tender sites around the joint, defined by a pressure pain threshold (PPT) of less than 4 
$\mathrm{kg} / \mathrm{cm} 2$ tested in the extended version of the Arendt-Nielsen peripatellar map (see below). Patients were considered highly sensitized when showing 3 tender sites (instead of 2) and reporting an increase of at least 1 point on an 11-point pain scale after 10 repeated pressure stimulation on the tenderest point around the knee. Knee OA patients with strong/severe pain showed 3 tender sites in the study by Arendt-Nielsen et al. [4].

A custom-made (in house) MRI compatible algometer $[15,20]$ was used to identify tender sites. The probe $\left(1 \mathrm{~cm}^{2}\right)$ was placed perpendicular to the selected anatomical sites and pressure was applied $(0.3 \mathrm{~kg} / \mathrm{s})$ until the participant defined the pressure as pain (or exceeded $4 \mathrm{~kg} / \mathrm{cm} 2$, when the site was considered a non-tender point). Pain was assessed twice on each site of the extended version of the Arendt-Nielsen peripatellar map and the mean of two measurements was estimated [4]. The extended map (Figure 1) included ten sites located in relation to bone landmarks from Arendt-Nielsen et al. [4] (sites 1 to 8) and Imamura et al. [17] (sites 9 and 10). Importantly, sites 3 (lateral interline), 7 (medial interline) and 8 (patella) were not considered in our assessment of spreading sensitization, as they form part of the joint.

Tenderness of the tibial site (site 10 in the map) was specifically evaluated in each participant and defined as painful intensity on an 11-point NRS to a pressure of 4 $\mathrm{kg} / \mathrm{cm} 2$ applied for $2 \mathrm{sec}$. This site was selected as the region to be stimulated during fMRI sessions because it is a frequently sensitized site [17] located relatively distant to the knee joint (centered at the tibial bone surface, $5 \mathrm{~cm}$ distal to the knee interline). Thus, eventual enhancement of evoked brain activity may genuinely be related to the sensitization phenomenon.

Temporal summation to repeated pressure stimulation was evaluated on the most sensitive site. Sequential stimulation consisted of 10 pressure stimuli (1s duration and $1 \mathrm{~s}$ 
interval) applied with the algometer at the pressure pain threshold level [4]. Patients rated their pain intensity in response to the first and last stimuli on an 11-point NRS.

\section{Painful stimulation tests during fMRI}

Test 1. Direct pressure stimulation on the articular interline. The test involved pressure stimulation on the medial articular interline at the tenderest point with the knee in the position of 60 degree flexion. A pulsed pressure of $2.5 \mathrm{~kg} / \mathrm{cm}^{2}$ was applied using our algometer in 11 blocks of 10 seconds including five pressure pulses per block with pulse duration of 1 second and stimulus interval of 1 second (Supplementary Figure 1). The intensity of $2.5 \mathrm{~kg} / \mathrm{cm}^{2}$ was selected as it consistently provoked moderate pain $(5-7$ points in an 11-point NRS) in knee OA patients in our previous study [15].

Test 2. Pressure stimulation on the anterior surface of the tibial region. This test involved pressure stimulation on the upper third of the anterior (medial) surface of the leg tibial region, $5 \mathrm{~cm}$ below the knee interline in the position of 60 degree flexion. A pulsed pressure of $4 \mathrm{~kg} / \mathrm{cm}^{2}$ was applied in 11 blocks of 10 seconds including 5 pressure pulses per block. The intensity of $4 \mathrm{~kg} / \mathrm{cm}^{2}$ was selected as the conventional stimulus intensity used to assess primary sensitization disorders [33].

Test 3. Painful heat stimulation on the forearm. This test was used to assess the extent to which pain sensitization in OA is a general phenomenon spreading to distant body areas and affecting other pain modalities as in primary forms of pain sensitization [34]. Contact heat stimuli applied on healthy forearm skin was carried-out using $45^{\circ} \mathrm{C}$ peaks, which are able to evoke mild-to-moderate pain in normal subjects [6]. The Contact Heat-Evoked Potential Stimulator (CHEPS) system (Medoc Ltd., Advanced Medical Systems) was used. During fMRI, painful heat stimulation was applied with a 
$27-\mathrm{mm}$ diameter thermode device on the right volar forearm in 11 blocks of $10 \mathrm{~s}$ including five $45^{\circ} \mathrm{C}$ spikes per block.

\section{Functional MRI acquisition}

A 1.5 Tesla Signa Excite system (General Electric, Milwaukee, WI, USA), equipped with an eight-channel phased-array head coil and single-shot echo planar imaging (EPI) software was used. Functional sequences consisted of gradient recalled acquisition in the steady state (time of repetition [TR], $2000 \mathrm{~ms}$; time of echo [TE], $50 \mathrm{~ms}$; pulse angle, $90^{\circ}$ ) within a field of view of $24 \mathrm{~cm}$, with a $64 \times$ 64-pixel matrix, and with a slice thickness of $4 \mathrm{~mm}$ (inter-slice gap, $1.5 \mathrm{~mm}$ ). Twenty-two interleaved slices, parallel to the anterior-posterior commissure line, were acquired to cover the whole-brain. The first four (additional) images in each run were discarded to allow the magnetization to reach equilibrium.

The three fMRI tests were equivalent in design: they each had a total duration of 6-min (180 brain volumes), which corresponded to 11 non-stimulation (baseline) blocks (20s) alternating with 11 painful stimulation blocks (10s). Each test concluded with a baseline block of 30s, after which participants rated their overall subjective pain experienced.

\section{Functional MRI analysis}

Image preprocessing. Imaging data were processed using MATLAB (The MathWorks Inc, Natick, Mass) and Statistical Parametric Mapping software (v8). Preprocessing involved conventional realignment procedures, spatial normalization and smoothing using a Gaussian filter (full-width half-maximum, $8 \mathrm{~mm}$ ). Data were normalized to the standard SPM-EPI template and resliced to $2 \mathrm{~mm}$ isotropic resolution in Montreal 
Neurological Institute (MNI) space. All image sequences were inspected for potential acquisition and normalization artifacts.

First-level (single-subject) analysis. The fMRI signal response at each voxel was modelled using study-specific regressors adjusted to the actual brain response to our pressure stimulation blocks with 4 s delay and 16s activation duration for both the knee interline and tibial tests, as characterized in previous experiments of independent samples $[15,20,27]$, and 4 s delay and 10 s activation duration for the forearm heat stimulation test.

Control of potential head motion effects. Contrasts 'painful>baseline' images were estimated including in the analysis six motion estimates as co-variables. Within-subject, censoring-based MRI signal artifact removal (scrubbing) [26] was used to discard motion-affected volumes. For each subject, inter-frame motion measurements [28] served as an index of data quality to flag volumes of suspect quality across the run. At points with inter-frame motion $>0.2 \mathrm{~mm}$, that corresponding volume, the immediately preceding and the succeeding two volumes were discarded. In addition, patients were excluded when showing evident head displacements (translations $>2 \mathrm{~mm}$, rotations $>2^{\circ}$ ) or residual motion artifacts in the first-level contrast image upon individual inspection (typically appearing in tissue boundaries, brain ventricles and white matter).

Group analysis. Resulting 1st-level contrast images were carried forward to 2nd-level random-effects (group) analyses in SPM. An ANOVA including all study groups was used to assess within-group effects and between-group differences. In addition, brain activation maps were correlated voxel-wise with clinical measurements of pain sensitization in OA patients including the number of tender sites around the assessed 
knee, the tenderness in the tibial site (pain evoked by 2 s tibial pressure stimulation) and amount of temporal pain summation.

Results were considered significant with clusters of $2.1 \mathrm{ml}$ (264 voxels) at a height threshold of $p<0.005$, which satisfied the family-wise error (FWE) rate correction of $\mathrm{P}_{\mathrm{FWE}}<0.05$ according to Monte Carlo simulations.

\section{Results}

\section{Behavioral results}

Thirty-three patients (55\%) showed regional spreading of pain (simple sensitization) and 19 patients (32\%) showed both regional spreading and temporal summation (Table 1 and Supplementary Figure 2). Notably, the proportion of females in the sensitized groups was higher than in the non-sensitized group (F/M ratio, 1.1 for non-sensitized patients, 7.3 for patients showing simple sensitization $\left[\chi^{2}=9.5 ; \mathrm{P}=0.003\right]$ and 5.3 for the high sensitization subgroup $\left.\left[\chi^{2}=5.1 ; \mathrm{P}=0.031\right]\right)$. Sensitized and non-sensitized OA patients did not differ in terms of radiological severity $(\mathrm{t}=0.5 ; \mathrm{p}=0.601)$, reported clinical pain severity in the affected knee at screening $(\mathrm{t}=1.9, \mathrm{p}=0.07)$ and proportion of cases receiving SSRIs antidepressants $(\chi 2=0.6 ; \mathrm{P}=0.459)$.

Subjective pain ratings during fMRI tests. Overall, sensitized patients ( $\mathrm{n}=33$ ) reported significantly more subjective pain than non-sensitized patients $(n=27)$ during both the interline fMRI test $(\mathrm{t}=2.3$ and $\mathrm{p}=0.027)$ and the tibial fMRI test $(\mathrm{t}=3.0$ and $\mathrm{p}=0.004)$. During painful heat stimulation on the volar forearm, the corresponding between-group differences were not statistically significant. 


\section{fMRI results}

\section{Brain response to painful stimulation on the knee articular interline}

Seventeen patients (and 6 control subjects) were excluded from the interline test analysis due to excessive head motion. The final sample included 20 sensitized patients (11 patients in the high sensitization subgroup) and 23 non-sensitized patients.

Intermittent pressure of $2.5 \mathrm{~kg} / \mathrm{cm}^{2}$ on the joint interline in symptomatic patients with knee OA evoked a brain response involving all the basic elements typically involved in pain perception. Figure 1 illustrates fMRI results obtained in the whole patient sample. The response included a sensory component with activation of the primary and second somatosensory cortex, the posterior insula and thalamus. The motor system was subsequently implicated with activation in the primary motor area, premotor cortex, supplementary motor area and basal ganglia. Activated areas concerning to the paralimbic (emotional) system included the anterior insula and anterior cingulate cortex. The response also included activation in the prefrontal lobe. Identical stimulus in the control subject group evoked a brain response mostly limited to the somatosensory cortices (Figure 2, Supplementary Figure 3 and Supplementary Table 1).

In the group comparison analysis, we found no significant differences in brain activation during interline testing between sensitized and non-sensitized patients (nonsensitized vs simple sensitization and non-sensitized vs the high sensitization subgroup). Figure 2 illustrates the (one-sample) results in simple sensitization, non-sensitized patients and control subjects. In the correlation analyses, we did not observe any association between clinical sensitization measurements and brain activation.

\section{Brain response to painful stimulation on the anterior tibial surface}


Nineteen patients (and 2 control subjects) were excluded from the tibia test analysis due to excessive head motion. The final sample included 21 sensitized patients (10 patients in the high sensitization subgroup) and 20 non-sensitized patients.

Intermittent pressure of $4 \mathrm{~kg} / \mathrm{cm}^{2}$ on the anterior tibial surface in OA patients also activated major elements typically involved in pain perception (Supplementary Table 2). However, activations were less robust and less extensive in non-sensitized patients and limited to the sensory cortices in control subjects (Figure 3 and Supplementary Figure 4). Compared with non-sensitized patients, the sensitized groups (both simple sensitization and high sensitization) showed greater activation in discrete painprocessing regions including the somatosensory cortices, supramarginal gyrus and insula. However, significant differences were also observed in the ventral aspect of the sensorimotor cortex and visual and auditory areas (Supplementary Figure 5, Supplementary Figure 6 and Supplementary Table 3).

Across the whole patient sample, brain activation during tibial pressure stimulation correlated significantly with clinical measurements of pain sensitization. The number of tender sites showed the most robust correlation pattern, involving a large part of the somatosensory strip extending to motor and parietal areas, the posterior insula and the supramarginal and angular gyri, the visual cortex and lateral temporal cortex, with righthemisphere predominance, and the ventral striatum bilaterally (Supplementary Table 3, Figure 4). Thus, this correlation implicated part of the regions typically involved in pain perception, but was not limited to core areas. The correlation with pain intensity evoked with pressure on the tibial region showed a similar, albeit less extensive, anatomical pattern. Temporal summation measurements showed no significant correlation with brain activation. 
As the proportion of females in the sensitized groups was higher than in the nonsensitized group, the analyses comparing patient groups and the correlations with clinical measurements of pain sensitization were also conducted adjusted for sex and additionally for age. We found a similar pattern of results after the adjustment (Supplementary Table 3).

Lastly, the analysis was also conducted adjusted for subjective pain scores reported by patients during the tibial pressure test (Supplementary Figure 7 and Supplementary Table 4). Interestingly, a notable part of the sensitization effect remained significant. These results further indicate that sensitized and non-sensitized patients differ not only in activation threshold, but also in the nature of brain activation extending to the general sensory system.

\section{Painful heat stimulation test (CHEPS)}

Nineteen patients (and 5 control subjects) were excluded from the CHEPS test analysis due to excessive head motion and 4 additional patients due to technical problems with CHEPS. The final sample included 18 sensitized patients (11 patients in the high sensitization subgroup) and 19 non-sensitized patients.

Heat stimulation on the volar forearm evoked a pattern of brain activation mostly involving bilateral frontoparietal opercula (extending to the supramarginal gyri), insula and basal ganglia. Activations were also identified in the medial frontal cortex and premotor cortex (Supplementary Table 5, Supplementary Figure 8). We did not find significant differences between sensitized and non-sensitized patients, and between patients and control subjects. Similarly, the correlation mapping analyses did not produce significant findings. 


\section{Discussion}

Thirty-three patients (55\%) in our sample showed regional spreading of pain (simple sensitization), while 19 patients (32\%) showed both regional spreading and temporal summation. The clinical data therefore further indicates that pain sensitization is a common phenomenon in symptomatic OA of the knee. Our imaging results illustrate the extent to which local pressure on the painful knee evokes a multidimensional neural response implicating sensory, emotional and cognitive-evaluative brain systems. Additionally and importantly, fMRI has shown that pressure on a sensitized, tender site (tibial region) away the joint itself activates regions typically involved in pain perception and extends beyond these regions to ventral sensorimotor, auditory and visual cortices.

Pain sensitization has a relevant spinal cord component that appears to amplify afferent activity generated in nerve terminals. The ultimate result is a net increase of the nociceptive inflow to the brain [34]. One consequence of spinal cord sensitization may therefore be the primary augmentation of neural activity in pain-related brain areas. We have identified higher activation in pain-related brain areas in sensitized patients compared with the non-sensitized group, consistent with the effect of spinal cord sensitization. Nevertheless, the brain response to pressure on the tender site also showed a qualitative alteration, as it extended to other sensory domains (i.e., visual and auditory) and to the sensorimotor cortex distant to the leg cortical representation. The sensitization response was mostly evident in the form of activation surrounding painrelated core sensory areas (i.e., primary and second somatosensory areas). In other 
words, the pattern suggests a spreading of brain activity to nearby general sensory (and primary motor) domains.

Differences between sensitized and non-sensitized patients in brain response to pressure stimulation were significant only for the tibial test, whereas the interline test was unable to capture the sensitization phenomenon. Thus, the identified brain alterations seem to more closely express changes associated with spreading sensitization. Interestingly, the sensitization effect on sensory areas remained significant to a large extend after adjusting for subjective pain scores, which suggests that some differences in brain activation are not a mere expression of a lower pain threshold in sensitized patients.

The anatomy of the cortical alteration identified in sensitized knee OA patients partly overlaps with the anatomy of spontaneous functional connectivity alterations identified in fibromyalgia, which is considered a primary form of pain sensitization. In our previous study [29], spontaneous pain in fibromyalgia patients was associated with reduced connectivity between second somatosensory cortex and primary somatosensory, visual and auditory cortices. Therefore, on the basis of fMRI results, primary sensitization in fibromyalgia and sensitization secondary to OA appear to overlap in terms of implicating sensory alterations beyond the traditional nociceptive system. The nature of such alterations may nevertheless be opposing between these conditions - with weakening of spontaneous sensory integration [29] together with weakening of the neural response during sensory stimulation in fibromyalgia [21], and excessive recruitment of sensory areas during painful stimulation in OA. Future studies will be needed to clarify the direct similarities and differences between them.

Sensitized patients were more commonly women in our study. This result is consistent with the higher prevalence of fibromyalgia in women [13] and with other evidence 
indicating greater sensitivity to experimental pain in women with knee OA compared with men $[3,9]$. Although women are at substantially higher risk for many clinical pain conditions, a compelling mechanistic understanding of this relationship is lacking [13]. More research into this issue is clearly needed, and may ultimately contribute to a better understanding of the pain sensitization phenomenon itself.

Our results should be distinguished from brain alterations predicting transitions to chronic pain. Neural changes associated with pain sensitization in our study mostly concerned posterior sensory areas and adjacent motor cortex. Whereas the transition to chronic pain is generally associated with changes in anterior corticolimbic brain regions related to reward and motivated behavior [8]. Moreover, clinical evidence of pain sensitization seems that is not a good predictor of pain chronification [31]. However, it is interesting that we observed a significant association between the number of tender sites reported and activation in a part of the ventral striatum, which is central to reward and motivation.

A limitation when assessing elderly participants with pain experimentation during fMRI is the risk of excessive head motion that may introduce imaging artifacts. In our case, this led to quite a number of patients being excluded from our final samples, although we prefer to adopt a conservative approach to head motion artifact correction. This issue is a general limitation of fMRI that may challenge its application for single-subject evaluations. It is also relevant to comment that heat stimulation on the forearm was applied using a stimulus temperature of $45^{\circ} \mathrm{C}$ that generated only mild pain (around the threshold generating pain sensations). We acknowledge that the test was not optimal to fully characterize brain responses to heat stimulation. However, we considered that it 
was adequate for detecting pain sensitization to this stimulus modality, as the sensitization phenomenon is expected to lower pain thresholds.

In summary, there is a current need to better understand pain sensitization phenomenon in order to more optimally understand and treat affected individuals. Our study provides a novel characterization of the brain response to sensitized pain in patients with knee OA. Its results indeed confirm that sensitized patients demonstrate an abnormally enhanced response to a gentle stimulation in regions typically involved in pain perception. However, nociceptive processing also appears to be distinctly altered in OA patients in the form of a regional spreading of evoked brain activity to general sensory, non-nociceptive areas. 


\section{Acknowledgments}

This study was supported in part by the Ministry of Economy and Competitiveness of Spain (grant PSI2014- 53524-P) and the Merck Investigator Studies Program (grant MISP-IISP41059). We thank to the Agency of University and Research Funding Management of the Catalonia Government for their participation in the context of Research Group SGR2014-1673. BJH is supported by a National Health and Medical Research Council of Australia (NHMRC) Clinical Career Development Award (1124472).

Dr. Pujol has nothing to disclose.

Dr. Martínez-Vilavella has nothing to disclose.

Dr. Llorente-Onaindia has nothing to disclose.

Dr. Harrison has nothing to disclose.

Dr. López-Solà has nothing to disclose.

Dr. López-Ruiz has nothing to disclose.

Dr. Blanco-Hinojo has nothing to disclose.

Dr. Benito has nothing to disclose.

Dr. Deus has nothing to disclose.

Dr. Monfort has nothing to disclose. 


\section{References}

1. Abaei M, Sagar DR, Stockley EG, Spicer CH, Prior M, Chapman V, Auer DP. Neural correlates of hyperalgesia in the monosodium iodoacetate model of osteoarthritis pain. Mol Pain 2016;12:pii-1744806916642445.

2. Altman R, Asch E, Bloch D, Bole G, Borenstein D, Brandt K, Christy W, Cooke TD, Greenwald R, Hochberg M. Development of criteria for the classification and reporting of osteoarthritis. Classification of osteoarthritis of the knee. Diagnostic and Therapeutic Criteria Committee of the American Rheumatism Association. Arthritis Rheum 1986;29:1039-49.

3. Arendt-Nielsen L, Eskehave TN, Egsgaard LL, Petersen KK, Graven-Nielsen T, Hoeck HC, Simonsen O, Siebuhr AS, Karsdal M, Bay-Jensen AC. Association between experimental pain biomarkers and serologic markers in patients with different degrees of painful knee osteoarthritis. Arthritis Rheumatol 2014;66:3317-26.

4. Arendt-Nielsen L, Nie H, Laursen MB, Laursen BS, Madeleine P, Simonsen $\mathrm{OH}$, Graven-Nielsen T. Sensitization in patients with painful knee osteoarthritis. Pain 2010;149:573-81.

5. Arendt-Nielsen L, Skou ST, Nielsen TA, Petersen KK. Altered central sensitization and pain modulation in the CNS in chronic joint pain. Curr Osteoporos Rep 2015;13:225-34.

6. Atlas LY, Bolger N, Lindquist MA, Wager TD. Brain mediators of predictive cue effects on perceived pain. J Neurosci 2010;30:12964-77. 
7. Baert IA, Lluch E, Mulder T, Nijs J, Noten S, Meeus M. Does pre-surgical central modulation of pain influence outcome after total knee replacement? A systematic review. Osteoarthritis Cartilage 2016;24:213-23.

8. Baliki MN, Apkarian AV. Nociception, pain, negative moods, and behavior selection. Neuron 2015;87:474-91.

9. Bartley EJ, King CD, Sibille KT, Cruz-Almeida Y, Riley JL 3rd, Glover TL, Goodin BR, Sotolongo AS, Herbert MS, Bulls HW, Staud R, Fessler BJ, Redden DT, Bradley LA, Fillingim RB. Enhanced pain sensitivity among individuals with symptomatic knee osteoarthritis: Potential sex differences in central sensitization. Arthritis Care Res (Hoboken) 2016;68:472-80.

10. Bellamy N, Buchanan WW, Goldsmith CH, Campbell J, Stitt LW. Validation study of WOMAC: A health status instrument for measuring clinically important patient relevant outcomes to antirheumatic drug therapy in patients with osteoarthritis of the hip or knee. J Rheumatol 1988;15:1833-40.

11. Cleeland CS, Ryan KM. Pain assessment: global use of the Brief Pain Inventory. Ann Acad Med Singapore 1994;23:129-38.

12. De Andrés J, Pérez-Cajaraville J, Lopez-Alarcón MD, López-Millán JM, Margarit C, Rodrigo-Royo MD, Franco-Gay ML, Abejón D, Ruiz MA, LópezGomez V, Pérez M. Cultural adaptation and validation of the painDETECT scale into Spanish. Clin J Pain 2012;28:243-53.

13. Fillingim RB, King CD, Ribeiro-Dasilva MC, Rahim-Williams B, Riley JL 3rd. Sex, gender, and pain: a review of recent clinical and experimental findings. $\mathrm{J}$ Pain 2009;10:447-85. 
14. Fingleton C, Smart K, Moloney N, Fullen BM, Doody C. Pain sensitization in people with knee osteoarthritis: a systematic review and meta-analysis. Osteoarthritis Cartilage 2015;23:1043-56.

15. Giménez M, Pujol J, Ali Z, López-Solà M, Contreras-Rodríguez O, Deus J, Ortiz H, Soriano-Mas C, Llorente-Onaindia J, Monfort J. Naproxen effects on brain response to painful pressure stimulation in patients with knee osteoarthritis: a double-blind, randomized, placebo-controlled, single-dose study. J Rheumatol 2014;41:2240-8.

16. Glover TL, Horgas AL, Fillingim RB, Goodin BR. Vitamin D status and pain sensitization in knee osteoarthritis: a critical review of the literature. Pain Manag 2015;5:447-53.

17. Imamura M, Imamura ST, Kaziyama HH, Targino RA, Hsing WT, de Souza LP, Cutait MM, Fregni F, Camanho GL. Impact of nervous system hyperalgesia on pain, disability, and quality of life in patients with knee osteoarthritis: a controlled analysis. Arthritis Rheum 2008;59:1424-31.

18. Kim SH, Yoon KB, Yoon DM, Yoo JH, Ahn KR. Influence of centrally mediated symptoms on postoperative pain in osteoarthritis patients undergoing total knee arthroplasty: A prospective observational evaluation. Pain Pract 2015;15:E46-53.

19. Lluch E, Torres R, Nijs J, Van Oosterwijck J. Evidence for central sensitization in patients with osteoarthritis pain: a systematic literature review. Eur J Pain 2014;18:1367-75. 
20. López-Solà M, Pujol J, Hernández-Ribas R, Harrison BJ, Ortiz H, Soriano-Mas C, Deus J, Menchón JM, Vallejo J, Cardoner N. Dynamic assessment of the right lateral frontal cortex response to painful stimulation. Neuroimage 2010;50:1177-87.

21. López-Solà M, Pujol J, Wager TD, Garcia-Fontanals A, Blanco-Hinojo L, Garcia-Blanco S, Poca-Dias V, Harrison BJ, Contreras-Rodríguez O, Monfort J, Garcia-Fructuoso F, Deus J. Altered functional magnetic resonance imaging responses to nonpainful sensory stimulation in fibromyalgia patients. Arthritis Rheumatol 2014;66:3200-9.

22. López-Solà M, Woo CW, Pujol J, Deus J, Harrison BJ, Monfort J, Wager TD. Towards a neurophysiological signature for fibromyalgia. Pain 2017;158:34-47.

23. Neogi T, Guermazi A, Roemer F, Nevitt MC, Scholz J, Arendt-Nielsen L, Woolf C, Niu J, Bradley LA, Quinn E, Law LF. Association of joint inflammation with pain sensitization in knee osteoarthritis: The Multicenter Osteoarthritis Study. Arthritis Rheumatol 2016;68:654-61.

24. O'Leary H, Smart KM, Moloney NA, Doody CM. Nervous system sensitization as a predictor of outcome in the treatment of peripheral musculoskeletal conditions: A systematic review. Pain Pract 2016 (in press, doi: 10.1111/papr.12484).

25. Petersen KK, Arendt-Nielsen L, Simonsen O, Wilder-Smith O, Laursen MB. Presurgical assessment of temporal summation of pain predicts the development of chronic postoperative pain 12 months after total knee replacement. Pain 2015;156:55-61. 
26. Power JD, Mitra A, Laumann TO, Snyder AZ, Schlaggar BL, Petersen SE. Methods to detect, characterize, and remove motion artifact in resting state fMRI. Neuroimage 2014;84:320-41.

27. Pujol J, López-Solà M, Ortiz H, Vilanova JC, Harrison BJ, Yücel M, SorianoMas C, Cardoner N, Deus J. Mapping brain response to pain in fibromyalgia patients using temporal analysis of FMRI. PLoS One 2009;4:e5224.

28. Pujol J, Macià D, Blanco-Hinojo L, Martínez-Vilavella G, Sunyer J, de la Torre R, Caixàs A, Martín-Santos R, Deus J, Harrison BJ. Does motion-related brain functional connectivity reflect both artifacts and genuine neural activity? Neuroimage 2014;101:87-95.

29. Pujol J, Macià D, Garcia-Fontanals A Blanco-Hinojo L, López-Solà M, GarciaBlanco S, Poca-Dias V, Harrison BJ, Contreras-Rodríguez O, Monfort J, GarciaFructuoso F, Deus J. The contribution of sensory system functional connectivity reduction to clinical pain in fibromyalgia. Pain 2014;155:1492-503.

30. Rakel B, Vance C, Zimmerman MB, Petsas-Blodgett N, Amendola A, Sluka KA. Mechanical hyperalgesia and reduced quality of life occur in people with mild knee osteoarthritis pain. Clin J Pain 2015;31:315-22.

31. Vachon-Presseau E, Centeno MV, Ren W, Berger SE, Tétreault P, Ghantous M, Baria A, Farmer M, Baliki MN, Schnitzer TJ, Apkarian AV. The Emotional Brain as a Predictor and Amplifier of Chronic Pain. J Dent Res 2016;95:605-12.

32. Wager TD, Atlas LY, Lindquist MA, Roy M, Woo CW, Kross E. An fMRIbased neurologic signature of physical pain. N Engl J Med 2013;368:1388-97. 
33. Wolfe F, Smythe HA, Yunus MB, Bennett RM, Bombardier C, Goldenberg DL, Tugwell P, Campbell SM, Abeles M, Clark P. The American College of Rheumatology 1990 Criteria for the Classification of Fibromyalgia. Report of the Multicenter Criteria Committee. Arthritis Rheum 1990;33:160-72.

34. Woolf CJ. Central sensitization: implications for the diagnosis and treatment of pain. Pain 2011;152:S2-15. 


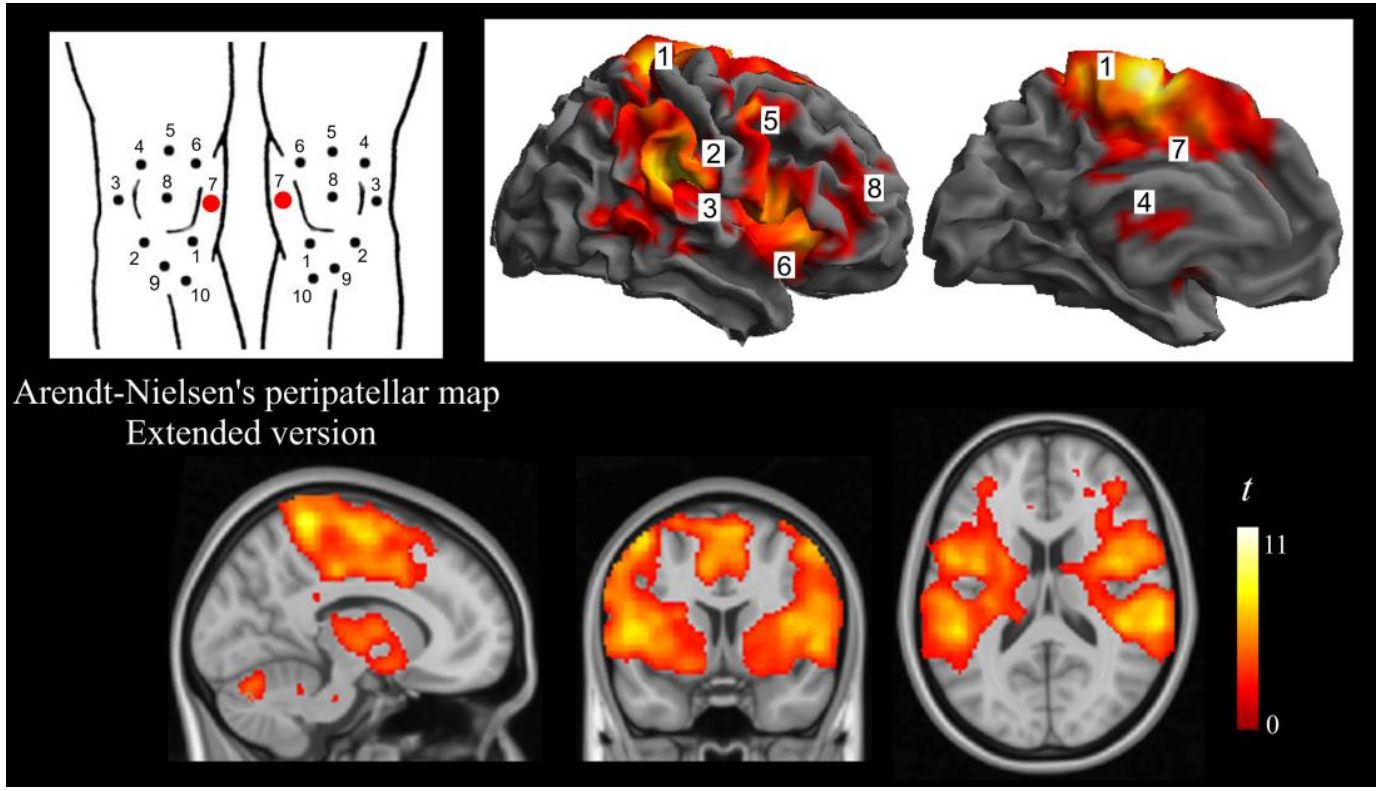

Figure 1. Brain response to pressure stimulation on the knee articular interline in the whole patient sample. The stimulus evoked a full activation of brain regions typically involved in pain perception with a sensory component involving the primary somatosensory area at the leg cortical representation (1), second somatosensory cortex extending to the supramarginal gyrus (2), posterior insula (3) and thalamus (4). Primary motor and premotor (5) areas were also activated. An emotional component involved activation of the anterior insula (6) and anterior cingulate cortex (7) and a cognitiveevaluative component implicated the prefrontal cortex (8). The right hemisphere corresponds to the right side of the coronal and axial orthogonal views (bottom). 


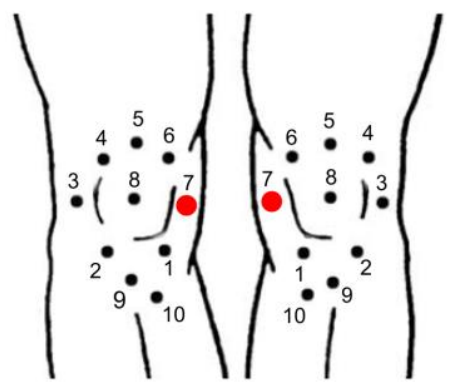

Arendt-Nielsen's peripatellar map Extended version

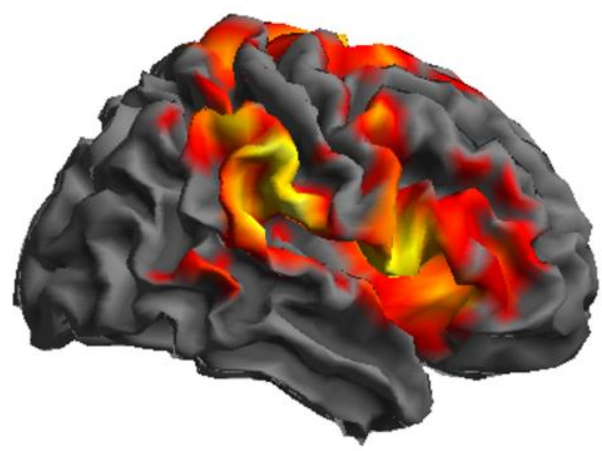

Non-sensitized

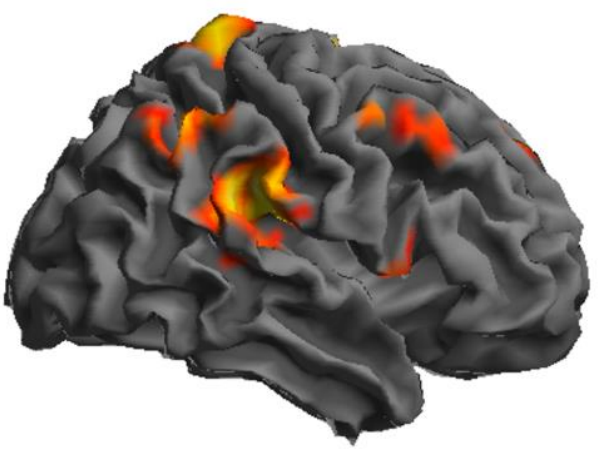

Control subjects

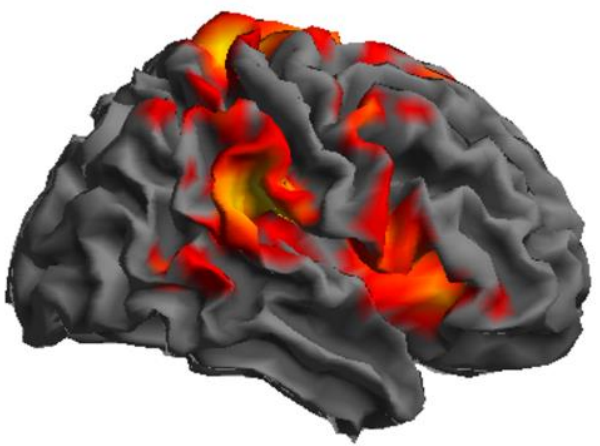

Sensitized

Figure 2. Brain response to pressure stimulation on the knee articular interline in sensitized patients, non-sensitized patients and control subjects. No significant differences were demonstrated between both patient groups. Activation in control subjects was mostly restricted to primary and second somatosensory cortices. 


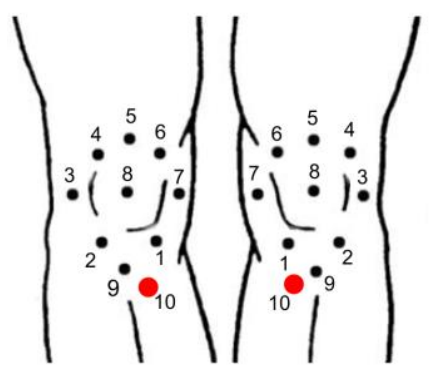

Arendt-Nielsen's peripatellar map Extended version

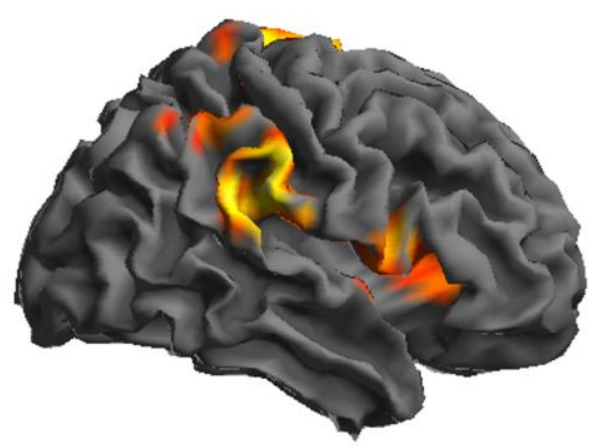

Non-sensitized

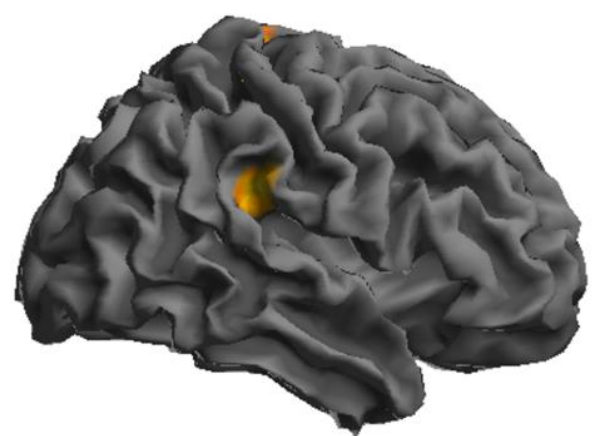

Control subjects

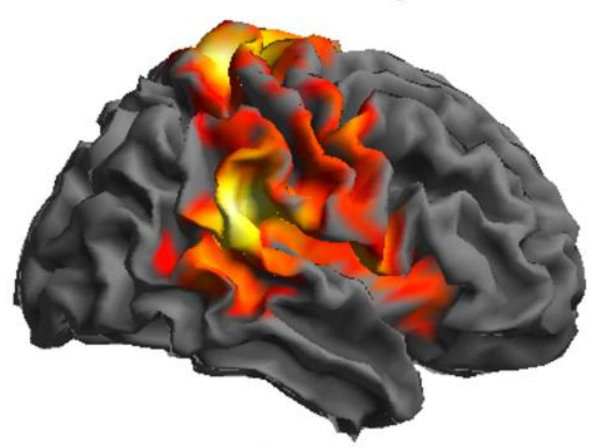

Sensitized

Figure 3. Brain response to pressure stimulation on the anterior tibial surface.

Sensitized patients showed an extensive activation, whereas significant changes in nonsensitized patients involved pain-processing core areas and activation in control subjects was limited to the primary and second somatosensory areas. 
Correlation with the number of tender sites (tibial test)
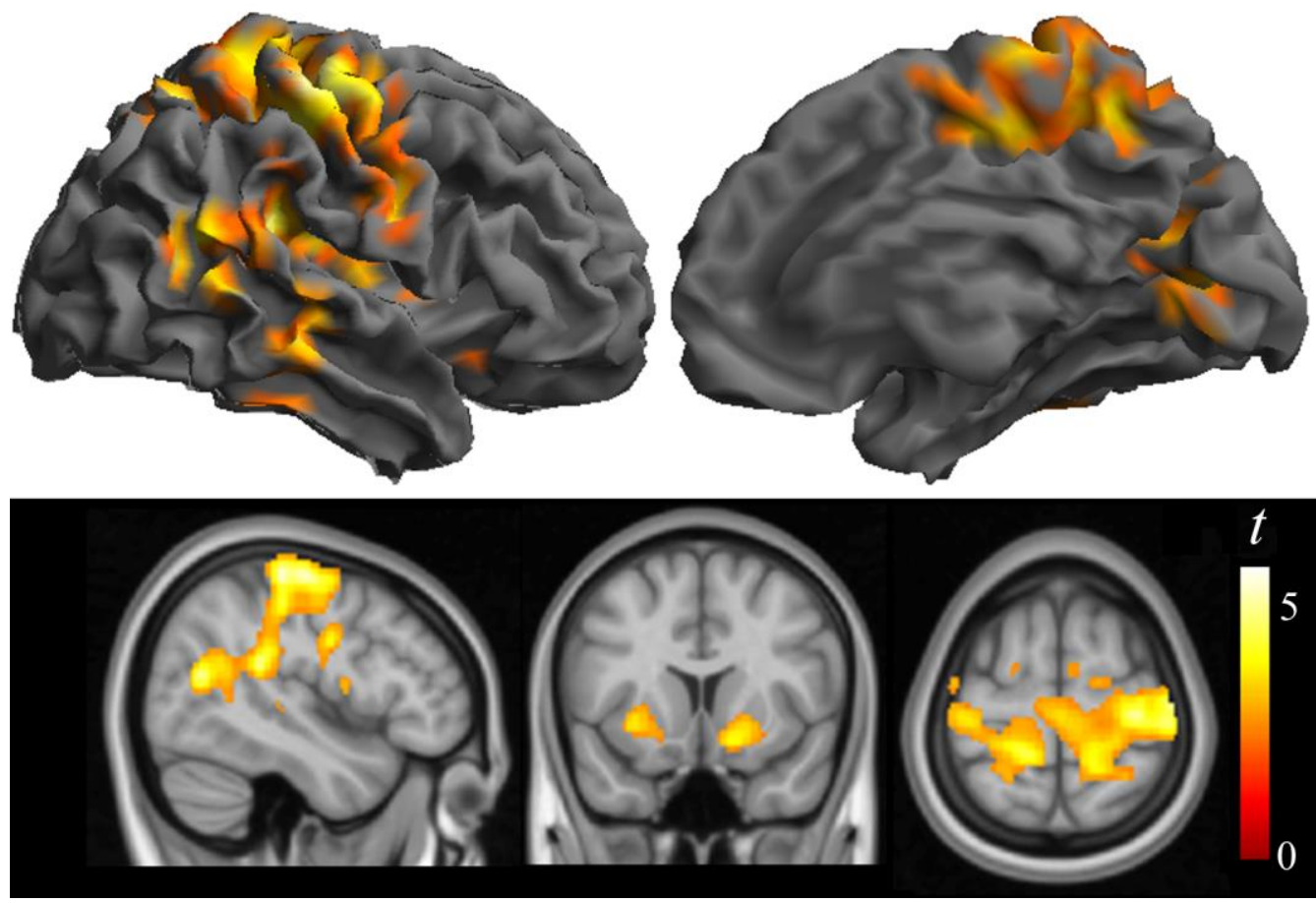

Figure 4. Map of the correlation between the number of tender sites on the Arendt-

Nielsen's peripatellar map and brain activation during the tibial fMRI test. The correlations implicated part of the regions typically involved in pain perception and also extended beyond these regions to the ventral sensorimotor cortex, auditory cortex and visual cortex, as well as the ventral aspect of the striatum. The right hemisphere corresponds to the right side of the coronal and axial orthogonal views (bottom). 
Table 1. Clinical Characteristics

\begin{tabular}{lcc|cc|c}
\hline \hline & $\begin{array}{c}\text { Control } \\
\text { subjects } \\
(\mathrm{N}=24)\end{array}$ & $\begin{array}{c}\text { Patients. } \\
\text { Total sample } \\
(\mathrm{N}=60)\end{array}$ & $\begin{array}{c}\text { Patients. } \\
\text { Non- } \\
\text { sensitized } \\
(\mathrm{N}=27)\end{array}$ & $\begin{array}{c}\text { Patients. } \\
\text { Simple } \\
\text { sensitization } \\
(\mathrm{N}=33)\end{array}$ & $\begin{array}{c}\text { Patients. High } \\
\text { sensitization } \\
\text { subgroup } \\
(\mathrm{N}=19)\end{array}$ \\
\hline \hline *Age, years mean & $62.8(7.7)$ & $66.7(7.8)$ & $68.1(6.5)$ & $65.3(8.6)$ & $66.4(8.8)$ \\
Sex, number F/M & $14 / 10$ & $43 / 17$ & $14 / 13$ & $29 / 4$ & $16 / 3$ \\
Radiological severity & $2.1(0.7)$ & $2.2(0.7)$ & $2.1(0.7)$ & $2.0(0.7)$ \\
WOMAC Index, total & $3.5(6.3)$ & $30.5(13.1)$ & $27.1(14.3)$ & $33.2(11.6)$ & $35.1(13.6)$ \\
PainDetect & $2.7(3.7)$ & $9.2(5.9)$ & $7.7(5.9)$ & $10.4(5.6)$ & $12.5(5.9)$ \\
$* *$ knee OA clinical pain & $1.3(1.9)$ & $5.1(1.1)$ & $4.8(1.0)$ & $5.3(1.1)$ & $5.3(1.3)$ \\
$* * *$ Tibial region pain & $1.0(1.4)$ & $6.0(2.5)$ & $4.5(2.4)$ & $7.2(1.8)$ & $7.9(1.4)$ \\
Number of tender points & $0.3(0.7)$ & $2.6(2.1)$ & $0.7(0.6)$ & $4.1(1.7)$ & $4.6(1.4)$ \\
Temporal Summation & $0.3(0.7)$ & $1.6(1.7)$ & $1.4(1.8)$ & $1.8(1.6)$ & $2.7(1.4)$ \\
Interline Pain during fMRI & $0.6(1.2)$ & $5.0(2.1)$ & $4.3(1.9)$ & $5.5(2.2)$ & $6.3(1.8)$ \\
Tibial Pain during fMRI & $2.3(2.2)$ & $6.9(2.1)$ & $6.0(2.2)$ & $7.6(1.8)$ & $7.8(2.0)$ \\
Forearm Pain during fMRI & $0.5(0.8)$ & $2.0(2.1)$ & $1.7(1.9)$ & $2.3(2.2)$ & $2.6(2.5)$ \\
\hline \hline Quantitative data are & & & &
\end{tabular}

Quantitative data are expressed as mean (SD). Pain was rated using an 11-point numerical rating scale. WOMAC, Western Ontario and McMaster Universities Osteoarthritis Index. *Patients and control subjects did not significantly differ in age and sex distribution. ${ }^{*}$ Severity score on item 5 from the Brief Pain Inventory at screening. ${ }^{* * *}$ Pain generated with a pressure of $4 \mathrm{~kg} / \mathrm{cm} 2$ during $2 \mathrm{sec}$. 


\section{Brain imaging of pain sensitization in patients with knee osteoarthritis}

\section{Supplementary Material}

Suppl. Figure 1. Pressure stimulation paradigm and study-specific regressor.

Suppl. Figure 2. Patient classification.

Suppl. Figure 3. Brain response to pressure stimulation on the knee articular interline.

Suppl. Figure 4. Brain response to pressure stimulation on the tibial region.

Suppl. Figure 5. Between-group differences in brain response to pressure stimulation on the tibial region in patients.

Suppl. Figure 6. Combined representation.

Suppl. Figure 7. Between-group differences in brain response to pressure stimulation on the tibial region adjusted for perceived pain.

Suppl. Figure 8. Brain response to painful heat stimulation on the volar forearm.

Suppl. Table 1. Brain activation during pressure stimulation on the articular interline.

Suppl. Table 2. Brain activation during pressure stimulation on the tibial surface.

Suppl. Table 3. Pain sensitization effect on brain response to tibial surface pressure.

Suppl. Table 4. Pain sensitization effect on brain response to tibial surface pressure adjusted for subjective pain ratings during fMRI

Suppl. Table 5. Brain activation during heat painful stimulation on the forearm. 


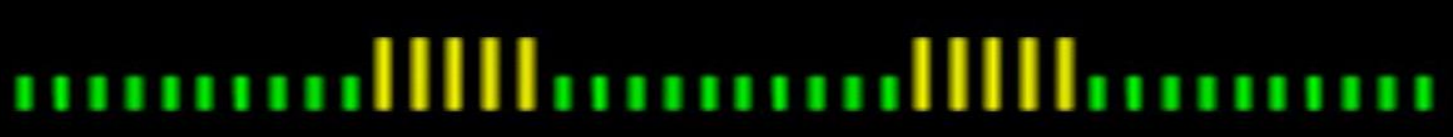

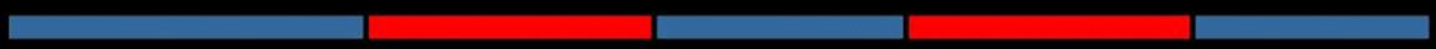
Rest
Activation
Rest
Activation
Rest

Supplementary Figure 1. Pressure stimulation paradigm and study-specific regressor. Yellow: original painful stimulus (10-s duration blocks [5 fMRI volumes with TR 2 s] including 5 pressure pulses each); green: original resting blocks (20-s duration, 10 fMRI volumes). Blue: periods modelled as baseline; red: periods modelled as activation. A 4-s delay was applied to the regressor. Two out of the 11 blocks included in each test are represented in the Figure. 


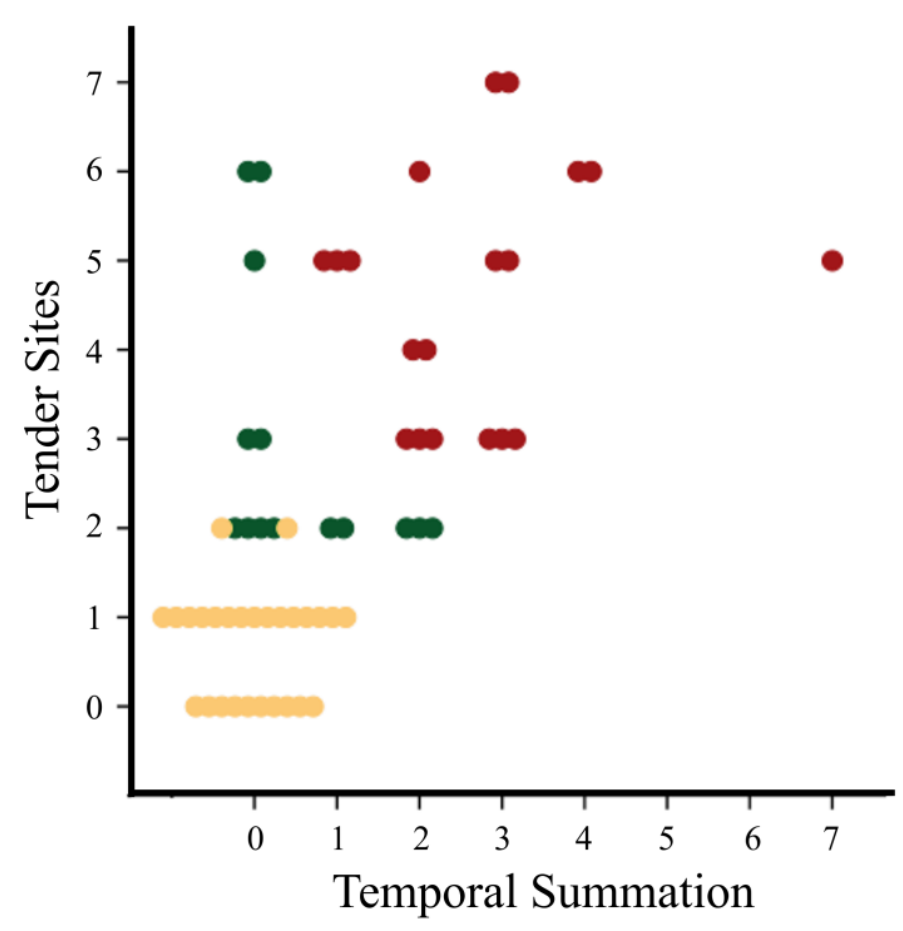

Supplementary Figure 2. Patient classification. Patients were considered sensitized to some degree (simple sensitization) when showing clinical evidence of altered sensations spread beyond the knee joint by manual palpation and a minimum of 2 tender sites (green and red dots). Temporal summation was not further considered (not applicable) to classify patients in the absence of spreading sensitization (brown dots). Note that 2 patients with 2 tender sites were classified in the non-sensitized group as they did not present clinical evidence (by manual palpation) of spreading sensitization. Patients were considered highly sensitized when showing 3 tender sites around the knee and reporting an increase of at least 1 point on an 11-point pain scale after repeated pressure stimulation on the tenderest point (red dots). 


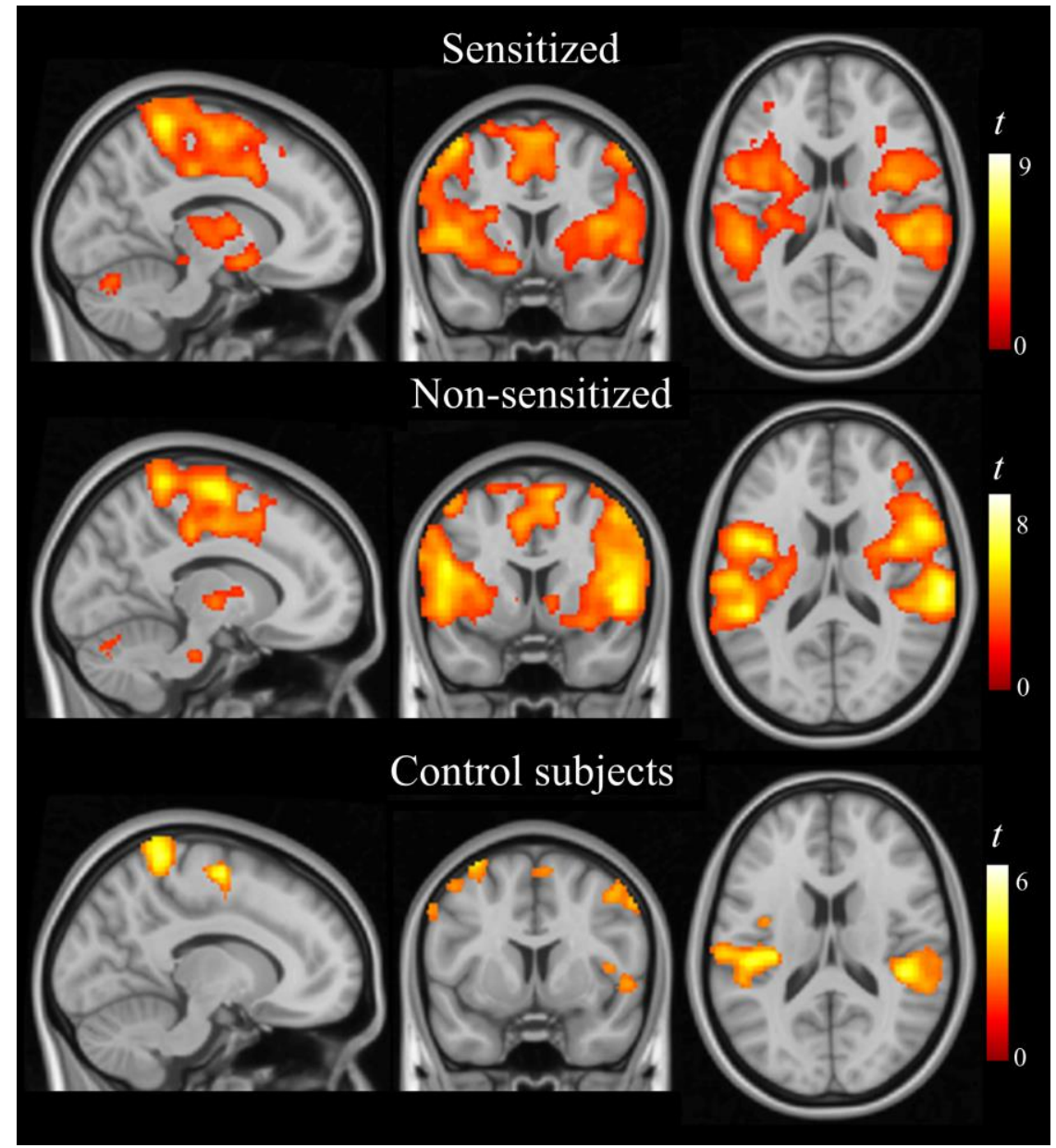

Supplementary Figure 3. Brain response to pressure stimulation on the knee articular interline in sensitized patients, non-sensitized patients and control subjects. The stimulus similarly implicated pain-related brain regions in both patient subgroups, whereas activation in control subjects was mostly restricted to primary and second somatosensory cortices. The right hemisphere corresponds to the right side of coronal and axial orthogonal views. 


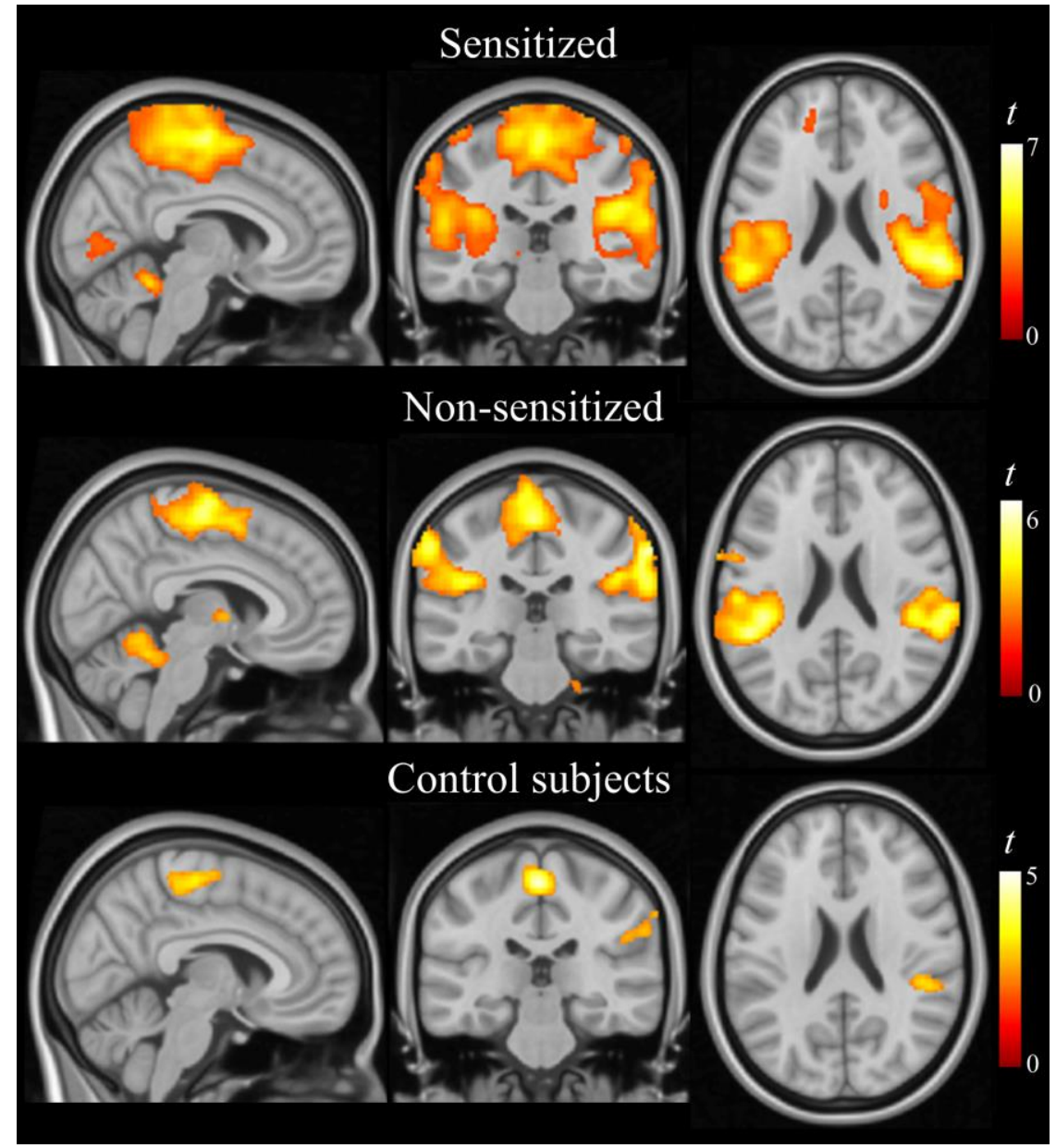

Supplementary Figure 4. Brain response to pressure stimulation on the tibial region in sensitized patients, non-sensitized patients and control subjects. The right hemisphere corresponds to the right side of coronal and axial orthogonal views. 


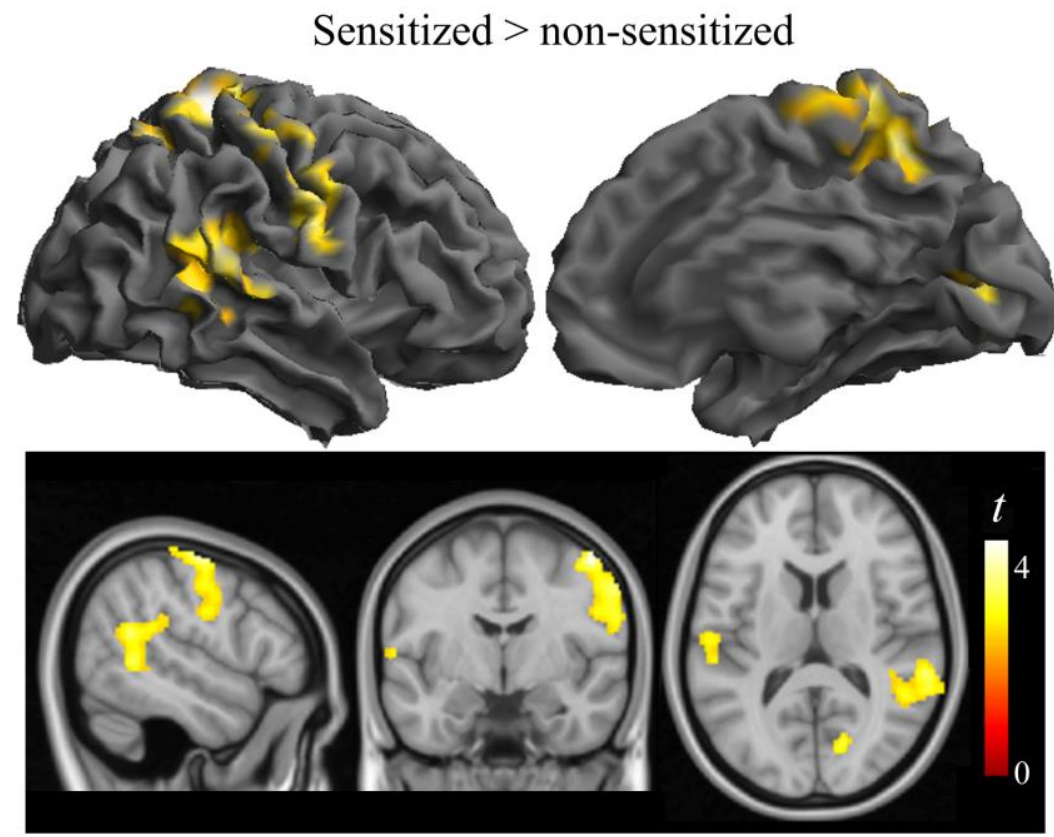

High sensitization $>$ non-sensitized
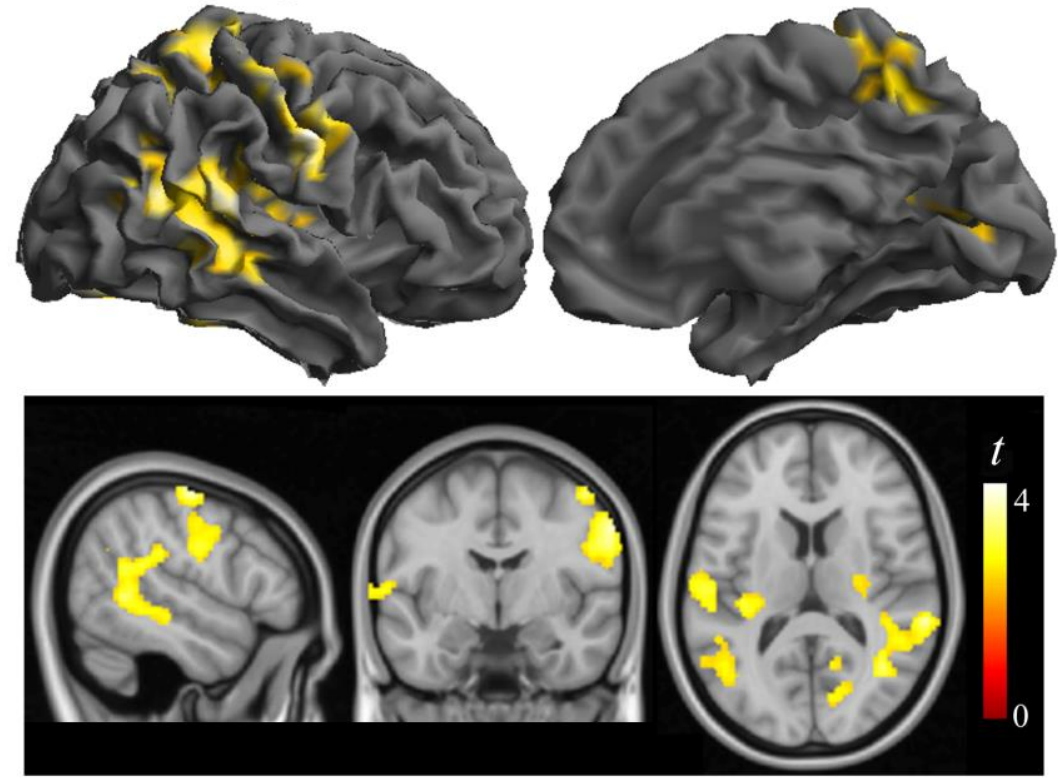

Supplementary Figure 5. Between-group differences in brain response to pressure stimulation on the tibial region in patients. The pattern generally implicated sensory cortices in the somatosensory, auditory and visual systems. The right hemisphere corresponds to the right side of coronal and axial orthogonal views. 


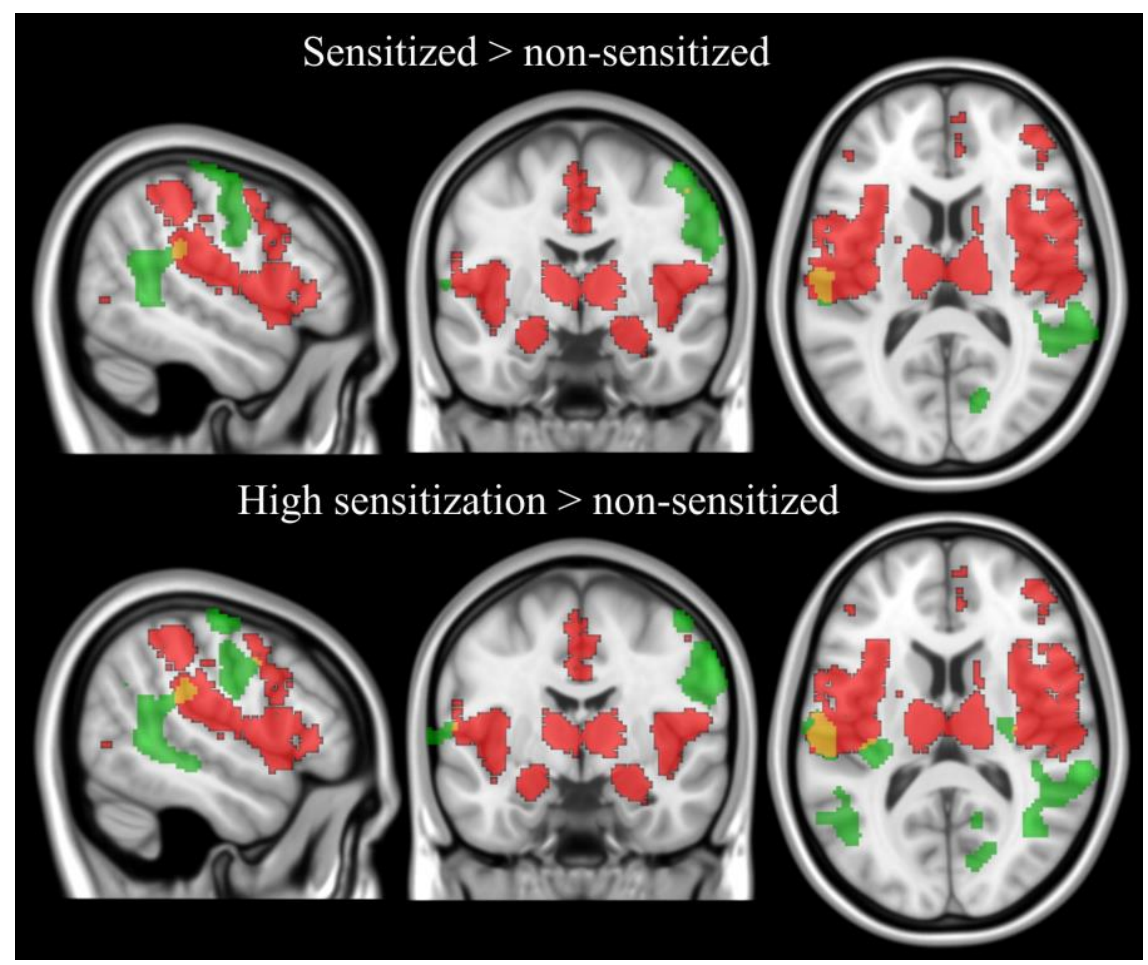

Supplementary Figure 6. Combined representation of between-group differences in brain response to tibial pressure (green) with regions typically involved in pain perception, according to a meta-analysis (red) (Yarkoni, T. (2014). Neurosynth core tools v0.3.1. Zenodo. http://doi.org/10.5281/zenodo.9925). Note the limited overlap between both maps (yellow). The right hemisphere corresponds to the right side of coronal and axial orthogonal views. 

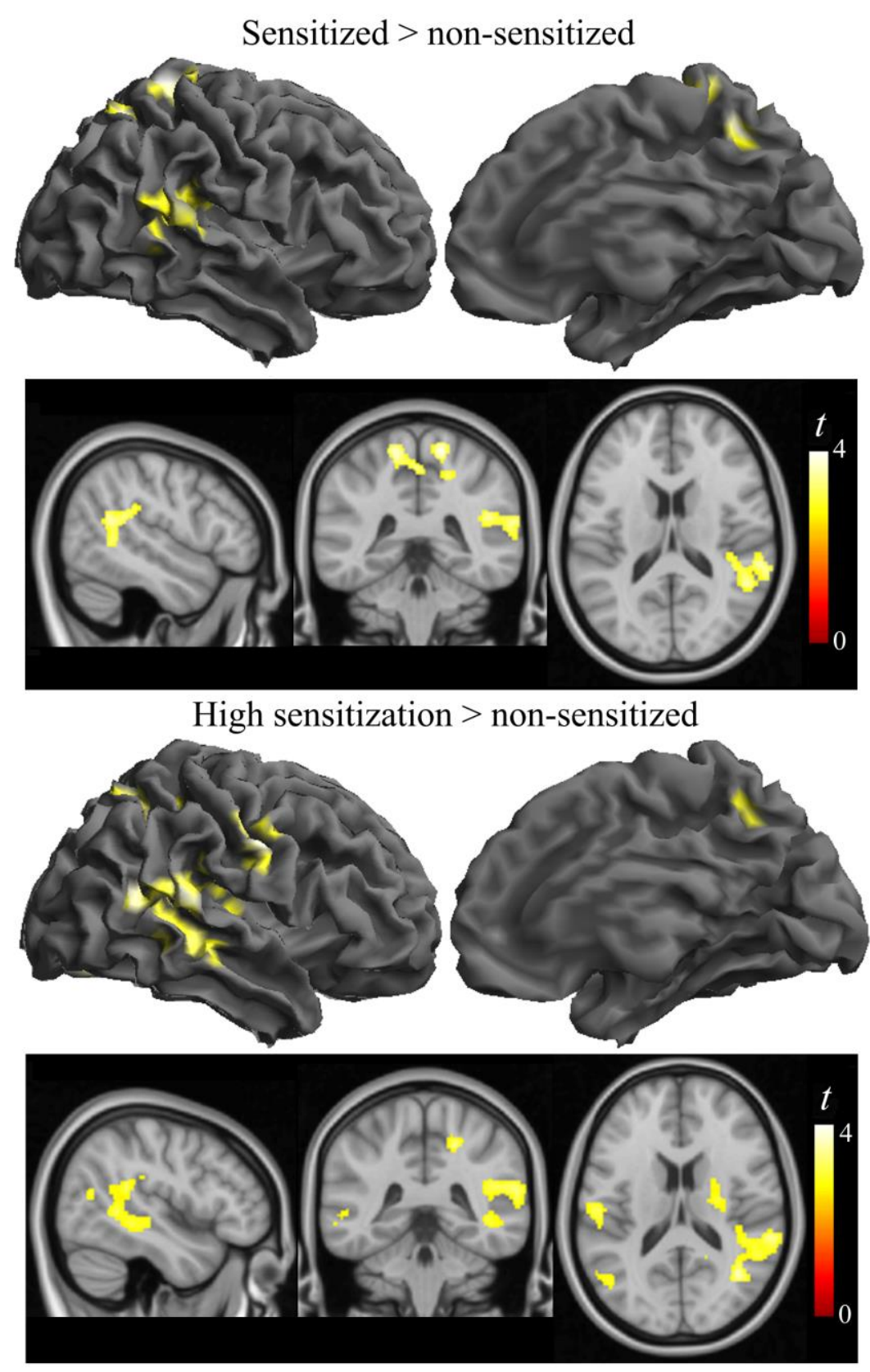

Supplementary Figure 7. Between-group differences in brain response to pressure stimulation on the tibial region adjusted for perceived pain. The right hemisphere corresponds to the right side of coronal and axial orthogonal views. 


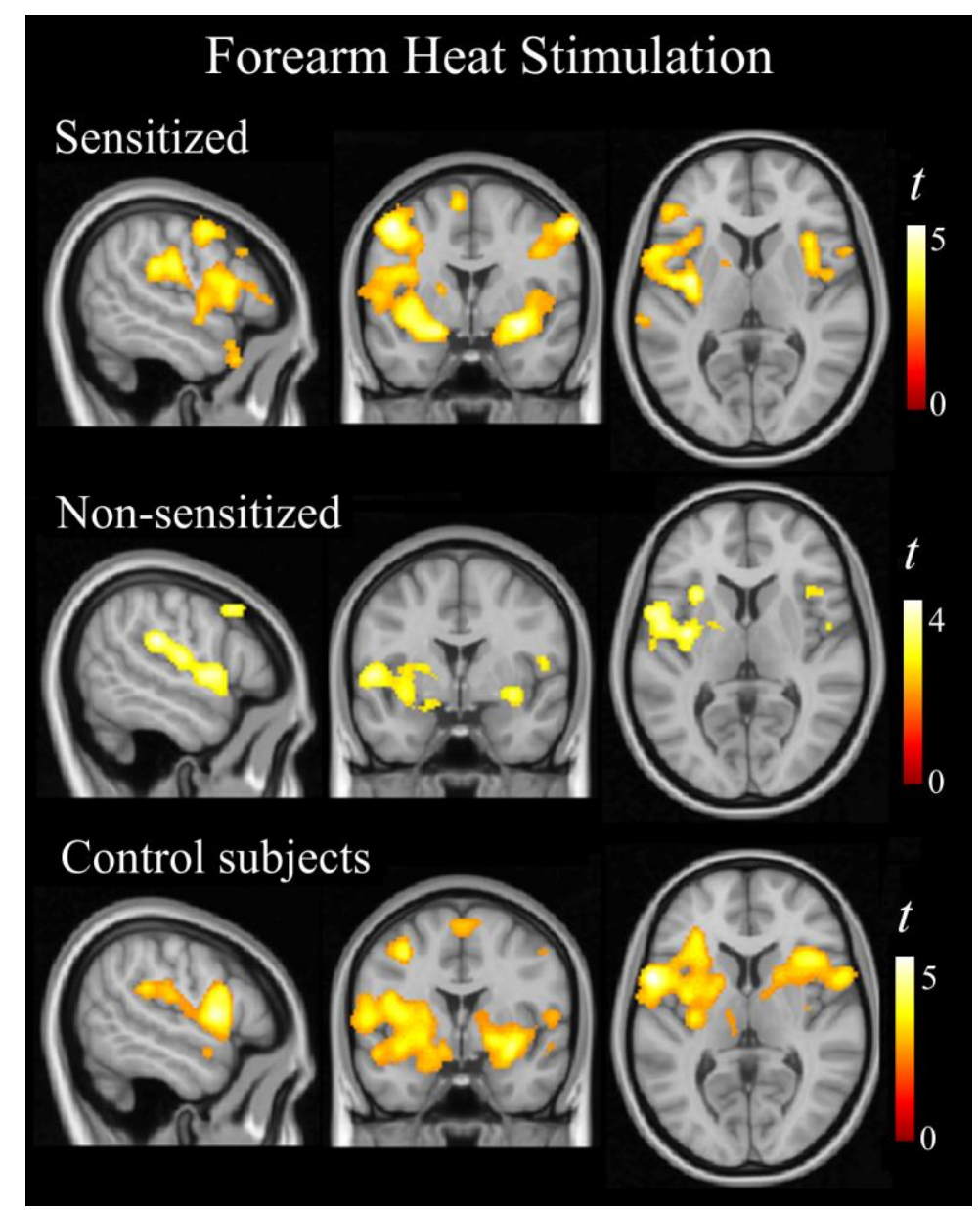

Supplementary Figure 8. Brain response to painful heat stimulation on the volar forearm in sensitized patients, non-sensitized patients and control subjects. The right hemisphere corresponds to the right side of coronal and axial views. 
Suppl. Table 1. Brain activation during pressure stimulation on the knee articular interline

\begin{tabular}{lcc}
\hline \hline Sensitized patients & MNI coordinates & $\mathrm{t}$ \\
\hline Left somatosensory cortex/primary motor cortex & $-18-4068$ & 10.3 \\
Right somatosensory cortex/primary motor cortex & $16-4068$ & 7.3 \\
ACC-SMA & $-8-1260$ & 8.2 \\
Left supramarginal gyrus/SII & $-48-3620$ & 7.0 \\
Right supramarginal gyrus/SII & $54-2624$ & 9.1 \\
Left anterior insula/operculum & -46182 & 6.0 \\
Right anterior insula/operculum & $4418-2$ & 5.6 \\
Prefrontal cortex & -344030 & 4.3 \\
Left basal ganglia & $-189-6$ & 3.9 \\
Right basal ganglia & $1612-10$ & 3.5 \\
Left thalamus & $-8-46$ & 4.9 \\
Right thalamus & $12-46$ & 5.1 \\
\hline Non-sensitized patients & & \\
\hline Left somatosensory cortex/primary motor cortex & & 7.1 \\
Right somatosensory cortex/primary motor cortex & $-14-4270$ & 5.5 \\
ACC-SMA & $18-4268$ & 8.2 \\
Left supramarginal gyrus/SII & $-6-660$ & 7.1 \\
Right supramarginal gyrus/SII & $-58-2224$ & 8.3 \\
Left anterior insula/operculum & $64-2418$ & 6.0 \\
Right anterior insula/operculum & -5480 & 7.3 \\
Prefrontal cortex & $4224-4$ & 5.0 \\
Left basal ganglia & 464428 & 4.3 \\
Right basal ganglia & $-22-4-8$ & 3.7 \\
Left thalamus & $1911-12$ & 4.0 \\
Right thalamus & $-14-120$ & 3.3 \\
\hline Control subjects & $6-140$ & 6.0 \\
\hline Left somatosensory cortex & & 6.3 \\
Right somatosensory cortex & & \\
Left supramarginal gyrus & $-16-4470$ & \\
Right supramarginal gyrus & $18-4270$ & \\
\hline \hline ACC, anteror cingulte gytus. SMA,supplementay motor & $-50-3622$ & \\
\hline
\end{tabular}

ACC, anterior cingulate gyrus. SMA, supplementary motor area. MNI, Montreal Neurological Institute. 
Suppl. Table 2. Brain activation during pressure stimulation on the tibial surface

\begin{tabular}{|c|c|c|}
\hline Sensitized patients & MNI coordinates & $\mathrm{t}$ \\
\hline Left somatosensory cortex & $-14-4266$ & 7.9 \\
\hline Right somatosensory cortex & $16-4266$ & 6.6 \\
\hline ACC/SMA & -12044 & 4.4 \\
\hline Left supramarginal gyrus/SII & $-52-4220$ & 5.9 \\
\hline Right supramarginal gyrus/SII & $58-3620$ & 7.0 \\
\hline Left anterior insula/operculum & $-2618-6$ & 4.2 \\
\hline Right anterior insula/operculum & 5028 & 5.3 \\
\hline Left basal ganglia & $-224-10$ & 4.4 \\
\hline Right basal ganglia & $226-10$ & 4.3 \\
\hline Left thalamus & $-14-180$ & 3.9 \\
\hline Right thalamus & $14-160$ & 3.5 \\
\hline Right ventral sensorimotor cortex & 50208 & 5.3 \\
\hline Visual cortex & $14-788$ & 4.8 \\
\hline Left lateral temporal/auditory cortex & $-64-104$ & 5.0 \\
\hline Right lateral temporal/auditory cortex & $66-242$ & 3.9 \\
\hline Cerebellum & $6-48-18$ & 4.8 \\
\hline \multicolumn{3}{|l|}{ Non-sensitized patients } \\
\hline Left somatosensory cortex & $-14-4272$ & 6.7 \\
\hline Right somatosensory cortex & $12-4472$ & 3.6 \\
\hline ACC/SMA & -6056 & 4.6 \\
\hline Left supramarginal gyrus/SII & $-50-4222$ & 5.7 \\
\hline Right supramarginal gyrus/SII & $60-3228$ & 5.9 \\
\hline Left anterior insula/operculum & -281610 & 4.5 \\
\hline Right anterior insula/operculum & 32224 & 4.0 \\
\hline Left basal ganglia & $-26-10-8$ & 4.6 \\
\hline Right basal ganglia & $208-16$ & 4.0 \\
\hline Left thalamus & $-4-82$ & 2.9 \\
\hline Right thalamus & $8-22$ & 3.8 \\
\hline Cerebellum & $2-52-12$ & 4.5 \\
\hline \multicolumn{3}{|l|}{ Control subjects } \\
\hline Left somatosensory cortex & $-12-4068$ & 4.5 \\
\hline Right supramarginal gyrus/SII & $52-3426$ & 4.3 \\
\hline
\end{tabular}

ACC, anterior cingulate gyrus. SMA, supplementary motor area. SII, second somatosensory cortex. MNI, Montreal Neurological Institute. 
Suppl. Table 3. Pain sensitization effect on brain response to tibial surface pressure

Between-group differences in brain activation

\begin{tabular}{|c|c|c|c|c|c|c|}
\hline $\begin{array}{l}\text { Sensitized patients }>\text { Non- } \\
\text { sensitized }\end{array}$ & $\mathrm{MNI}$ & $\mathrm{t}$ & $\begin{array}{l}\mathrm{MNI} \\
\text { Adj.* }\end{array}$ & Adj.* & $\begin{array}{l}\text { MNI } \\
\text { Adj.** }\end{array}$ & $\begin{array}{c}\mathrm{t} \\
\text { Adj.** }\end{array}$ \\
\hline L dorsal sensorimotor cortex & $-14-4064$ & 4.0 & $-16-4064$ & 3.7 & $-16-4064$ & 4.2 \\
\hline $\mathrm{R}$ dorsal sensorimotor cortex & $16-4064$ & 4.2 & $16-4466$ & 3.9 & $16-4266$ & 4.3 \\
\hline$R$ ventral sensorimotor cortex & $60-832$ & 3.6 & $62-830$ & 3.3 & $60-832$ & 3.6 \\
\hline $\begin{array}{l}\text { L supramarginal gyrus/Posterior } \\
\text { insula }\end{array}$ & $-56-1814$ & 3.3 & $-56-1814$ & 3.0 & $-56-1814$ & 3.5 \\
\hline $\begin{array}{l}\text { R supramarginal gyrus/ } \\
\text { Posterior insula }\end{array}$ & $62-3614$ & 3.8 & $62-3814$ & 4.0 & $60-3614$ & 4.4 \\
\hline Visual cortex & $14-788$ & 4.0 & $14-788$ & 3.3 & $14-788$ & 4.1 \\
\hline L lateral temporal/auditory cortex & $-56-284$ & 3.3 & $-54-284$ & 3.3 & $-56-284$ & 3.4 \\
\hline $\mathrm{R}$ lateral temporal/auditory cortex & $66-260$ & 3.5 & $66-240$ & 3.3 & $64-262$ & 3.6 \\
\hline
\end{tabular}

\section{High sensitization > Non-} sensitized

\begin{tabular}{|c|c|c|c|c|c|c|}
\hline L dorsal sensorimotor cortex & $-4-4260$ & 3.3 & $-6-4458$ & 3.1 & $-6-4458$ & 3.3 \\
\hline $\mathrm{R}$ dorsal sensorimotor cortex & $16-3864$ & 3.7 & $16-4064$ & 3.5 & $16-4064$ & 3.7 \\
\hline $\mathrm{R}$ ventral sensorimotor cortex & $62-840$ & 4.3 & $62-842$ & 4.2 & $62-842$ & 4.4 \\
\hline $\begin{array}{l}\text { L supramarginal gyrus/Posterior } \\
\text { insula }\end{array}$ & $-48-6618$ & 3.2 & $-50-6418$ & 3.1 & $-50-6418$ & 3.3 \\
\hline $\begin{array}{l}\text { R supramarginal gyrus/Posterior } \\
\text { insula }\end{array}$ & $52-4818$ & 3.4 & $54-4818$ & 3.4 & $52-4618$ & 3.7 \\
\hline Visual cortex & $-28-80-14$ & 3.9 & $-30-80-14$ & 3.5 & $-30-80-14$ & 3.7 \\
\hline L lateral temporal/auditory cortex & $-56-286$ & 3.3 & $-54-286$ & 3.3 & $-54-286$ & 3.3 \\
\hline $\mathrm{R}$ lateral temporal/auditory cortex & $40-28-4$ & 3.3 & $40-28-4$ & 3.3 & $40-284$ & 3.6 \\
\hline \multicolumn{7}{|c|}{ Correlation analysis } \\
\hline \multicolumn{7}{|l|}{ Number of tender sites } \\
\hline $\mathrm{R}$ medial sensorimotor cortex & $16-4464$ & 4.2 & $16-4464$ & 3.5 & $16-4464$ & 4.1 \\
\hline L medial sensorimotor cortex & $-16-3866$ & 4.6 & $-16-4066$ & 4.0 & $-16-4066$ & 4.5 \\
\hline L dorsolateral sensorimotor cortex & $-38-2454$ & 3.9 & $-40-2466$ & 3.4 & $-38-2454$ & 3.8 \\
\hline $\mathrm{R}$ dorsolateral sensorimotor cortex & $36-2858$ & 5.9 & $36-3058$ & 5.2 & $36-2858$ & 5.8 \\
\hline R ventral sensorimotor cortex & $50-430$ & 4.3 & $50-232$ & 3.9 & $50-430$ & 4.3 \\
\hline $\begin{array}{l}\text { Right posterior insula/ } \\
\text { supramarginal gyrus/angular gyrus }\end{array}$ & $36-2422$ & 4.4 & $36-2420$ & 4.3 & $36-2422$ & 4.3 \\
\hline Visual cortex & $8-720$ & 4.3 & $8-702$ & 3.7 & $8-720$ & 4.2 \\
\hline $\begin{array}{l}\text { Right temporal lateral/auditory } \\
\text { cortex }\end{array}$ & $62-28-8$ & 4.3 & $62-28-8$ & 4.3 & $62-28-8$ & 4.5 \\
\hline $\mathrm{R}$ ventral striatum & $1414-12$ & 4.1 & $206-8$ & 4.0 & $2016-8$ & 4.2 \\
\hline Left ventral striatum & $-3010-4$ & 3.9 & $-3010-4$ & 3.6 & $-3010-4$ & 3.9 \\
\hline
\end{tabular}

MNI, Montreal Neurological Institute. *Adjusted by sex. ${ }^{* *}$ Adjusted by age. L, left. R, right. 
Suppl. Table 4. Pain sensitization effect on brain response to tibial surface pressure adjusted for subjective pain ratings

\begin{tabular}{|c|c|c|c|c|c|c|}
\hline \multicolumn{7}{|c|}{ Between-group differences in brain activation } \\
\hline $\begin{array}{l}\text { Sensitized patients > Non- } \\
\text { sensitized }\end{array}$ & $\mathrm{MNI}$ & $\mathrm{t}$ & $\begin{array}{l}\mathrm{MNI} \\
\text { Adj.* }\end{array}$ & $\begin{array}{c}\mathrm{t} \\
\text { Adj. }\end{array}$ & $\begin{array}{c}\mathrm{MNI} \\
\text { Adj.** }\end{array}$ & $\underset{\mathrm{t}}{\mathrm{Adj} . * *}$ \\
\hline L dorsal sensorimotor cortex & $-14-4064$ & 3.5 & - & - & $-14-4062$ & 3.6 \\
\hline R dorsal sensorimotor cortex & $16-4266$ & 3.7 & $16-4466$ & 3.5 & $16-4266$ & 3.8 \\
\hline $\begin{array}{l}\text { R supramarginal gyrus/ } \\
\text { Posterior insula }\end{array}$ & $60-3614$ & 3.4 & $60-3614$ & 3.5 & $60-3614$ & 3.9 \\
\hline $\mathrm{R}$ lateral temporal/auditory cortex & - & - & - & - & $66-240$ & 3.2 \\
\hline \multicolumn{7}{|l|}{$\begin{array}{l}\text { High sensitization > Non- } \\
\text { sensitized }\end{array}$} \\
\hline $\mathrm{R}$ dorsal sensorimotor cortex & $20-3848$ & 3.5 & $20-3848$ & 3.4 & $16-4064$ & 3.3 \\
\hline R ventral sensorimotor cortex & $62-842$ & 4.1 & - & - & $62-842$ & 4.1 \\
\hline $\begin{array}{l}\text { L supramarginal gyrus/Posterior } \\
\text { insula }\end{array}$ & $-50-6620$ & 3.2 & - & - & $-50-6618$ & 3.2 \\
\hline $\begin{array}{l}\text { R supramarginal gyrus/Posterior } \\
\text { insula }\end{array}$ & $52-4816$ & 3.2 & $54-4818$ & 3.2 & $52-4618$ & 3.5 \\
\hline Visual cortex & $-30-80-14$ & 3.6 & $-30-80-14$ & 3.4 & $-28-80-14$ & 3.6 \\
\hline L lateral temporal/auditory cortex & $-54-286$ & 3.0 & - & - & $-54-286$ & 3.0 \\
\hline $\mathrm{R}$ lateral temporal/auditory cortex & $40-28-4$ & 3.3 & $40-28-4$ & 3.2 & $40-28-4$ & 3.5 \\
\hline
\end{tabular}

MNI, Montreal Neurological Institute. *Adjusted by sex. **Adjusted by age. L, left. R, right. 
Suppl. Table 5. Brain activation during heat painful stimulation on the forearm

\begin{tabular}{lcc}
\hline \hline Sensitized patients & MNI & $\mathrm{t}$ \\
\hline Left supramarginal gyrus/SII & $-58-2226$ & 4.9 \\
Frontal operculum & -541416 & 4.1 \\
Left premotor cortex & -48248 & 5.6 \\
Right premotor cortex & 58448 & 5.2 \\
Medial frontal cortex & -2858 & 3.8 \\
Left insula/ basal ganglia & $-320-12$ & 5.5 \\
Right insula/ basal ganglia & $300-12$ & 4.8 \\
\hline Non-sensitized patients & & \\
\hline Left supramarginal gyrus/SII & & 4.5 \\
Right supramarginal gyrus/SII & $-54-2824$ \\
Left insula/ basal ganglia & $64-1620$ & 4.1 \\
Right insula/ basal ganglia & -28166 & 3.8 \\
Left prefrontal cortex & $3414-2$ & 3.5 \\
Right prefrontal cortex & -442838 & 3.3 \\
\hline Control subjects & 482838 & 3.2 \\
\hline Left supramarginal gyrus/SII & & \\
Right supramarginal gyrus/SII & & 5.6 \\
Left frontal operculum & $-66-2232$ & 4.5 \\
Right frontal operculum & $58-1828$ & 5.8 \\
Premotor cortex & -5888 & 4.2 \\
Left medial frontal cortex & 5888 & 5.5 \\
Left insula/ basal ganglia & $-34-248$ & 3.9 \\
Right insula/ basal ganglia & -81050 & 4.8 \\
Periaqueductal grey (PAG) & $-2820-8$ & 4.6 \\
\hline \hline SII second somatosensory cortex. & 40206 & 3.8 \\
\hline
\end{tabular}

SII, second somatosensory cortex. MNI, Montreal Neurological Institute. 